\title{
NE PAS CRISPER
}

Ne pas crisper les paupières

$\mathrm{Ne}$ pas se révéler

Faire semblant de ne pas vouloir

La voir passer dans le couloir

L'avoir assez dans la mémoire

$\mathrm{Ne}$ pas vouloir vouloir

David H. Madsen

Duke University

\section{LA GUERRE}

L'image jaillit d'un rêve

D'armes blanches dressées debout

De la pointe de chacune pend

Un lambeau de vieux sang

D'une Iumière dure qui révèle

De la terre pendue et morte

où sont des barbes éparpillées partout

Et là-dessous

De la chaire statuaire

A moitié enfoncée dans des trous

Rien ne bouge

Silence

Elizabeth P. Blackford

California State University at Northridge 